\title{
Enzyme inhibitors, synthesis and approach to mechanism
}

\author{
M. Isobe,* K. Tsuboi, S. Hosokawa, M. Bamba, K. Kira, S. Shibuya, \\ I. I. Ohtani, T. Nishikawa, Y. Ichikawa \\ Laboratory of Organic Chemistry, School of Agricultural Sciences \\ Nagoya University, Chikusa, Nagoya 464-01, Japan
}

Abstract. Synthetic approach toward channel protein inhibitors (tetrodotoxin, ciguatoxin) and protein phosphatase inhibitors (tautomycin) is discussed with special reference to the stereochemical control.

Stereochemical control in organic synthesis is the major interest in the industrial production as well as in the basic studies directed to understand the nature of organic molecules. A-strain has been discussed since Johnson's substituted exo-olefin of the cyclohexane system was reported in 1965 . This concept was expanded to an acyclic case as illustrated in Fig. 1, in which the most stable conformer is the one with the least bulky substituent $(\mathrm{H})$ in the plane of the olefin. One face of this plane contains an oxygen atom, that acts as an anchor for metal chelation, while the other is activated by the inherent polarization of the C-O bond. In this paper, both the cyclic and acyclic cases are discussed.

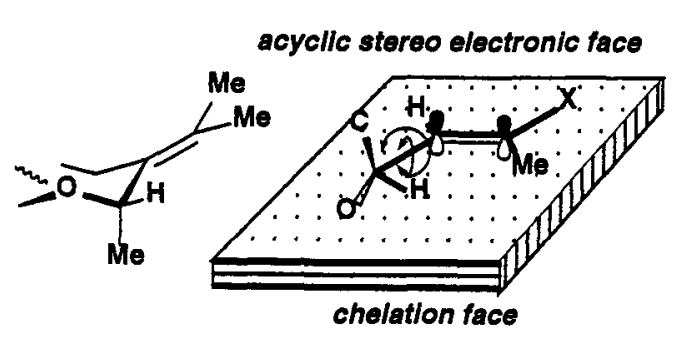

Fig 1

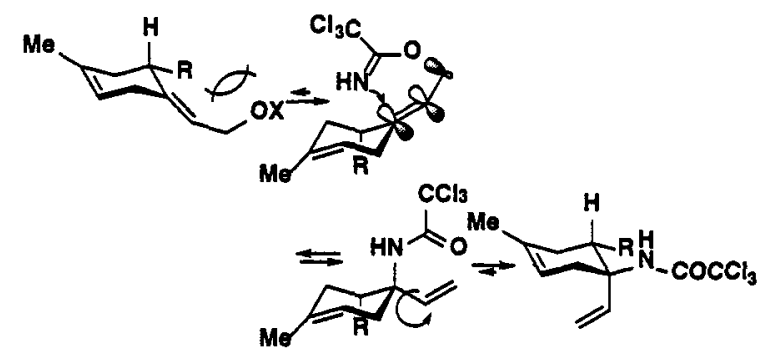

Scheme 1

Scheme 1 illustrates the [3.3]sigmatropic rearrangement $(5 \rightarrow>6)$, in which the A-strain renders the conformation of the reactant. The repulsion between equatorial $\mathrm{R}$ and co-planar $\mathrm{CH}_{2} \mathrm{OX}$ promotes the equilibrium toward axial- $R$ conformation, which is necessary as a transition state for the rearrangement. The resulting intermediate having two axial substituents, changes its conformation into the bis-equatorial one; thus, the equilibrium shifts in the direction where the nitrogen occupies the more hindered position.
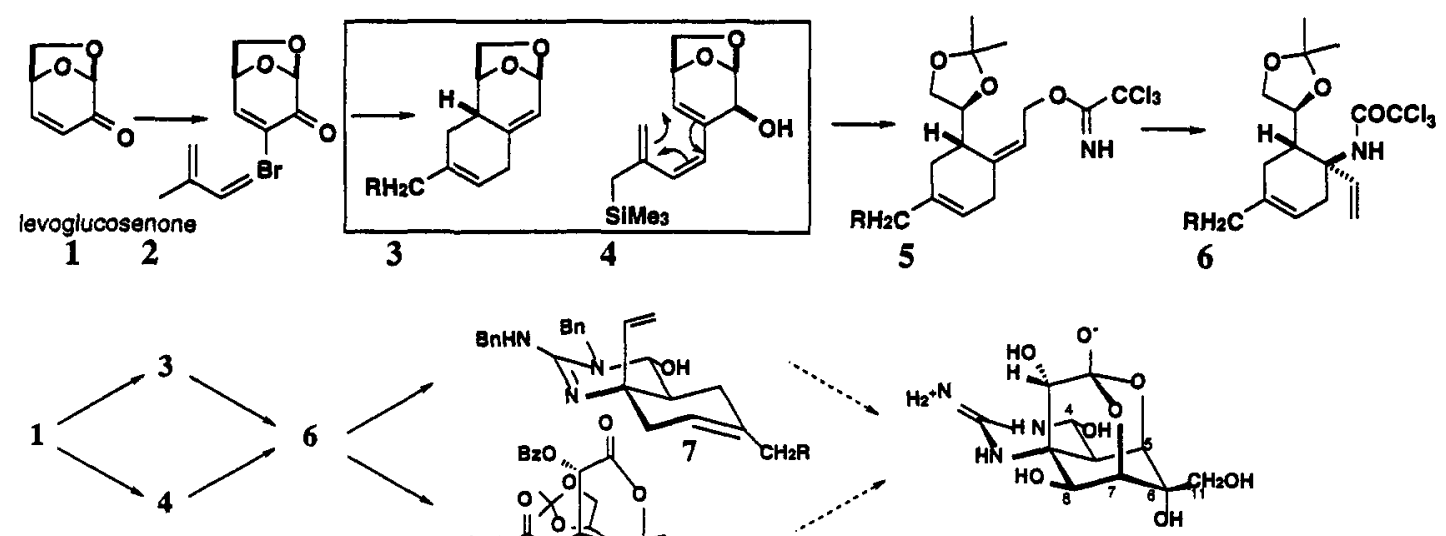

Tetrodotoxin 9 
The chiral cyclohexane ring had been synthesized for the synthesis directed towards (-)-tetrodotoxin via a Diels-Alder cycloaddition of bromo levoglucosenone to isoprene. 1,2 Since the reactivity of DA addition provided a limitation to this strategy, we recently employed an electrocyclic reaction of the corresponding triene. For the successful cyclization of this triene its conformation is significant, so that two of the 1,6-ends of 1,3,5-triene have to be close enough to overlap their $\pi$-orbitals. Allylic strain in this case prevents this conformation if $O R_{1}$ is repulsive to $R_{2}$. We found that simple cis-olefin $\left(11 R_{2}=H\right)$ gave only moderate yield of the cyclization product, while the triene with trimethylsilyl $\left(\mathbf{1 1} \mathbf{R}_{2}=\mathrm{SiMe}\right)$ gave only $8 \%$ yield of 12 . Attractive interaction was found, in fact, with the corresponding tin compound (11 $R_{2}=\mathrm{H}$ ) which gave 12 in $90 \%$ yield. The stereochemistry was established from noe experiments as in 13.
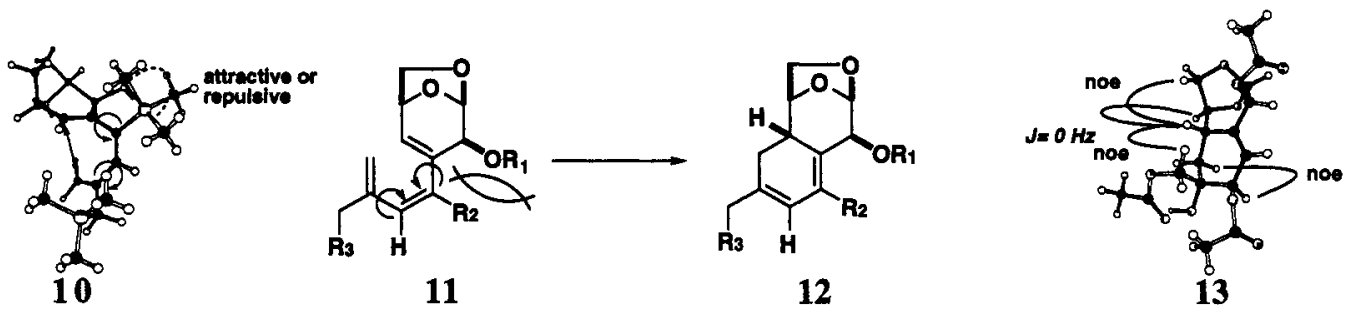

The following Scheme 3 summarizes the above discussion. Further functionalization for tetrodotoxin and the final guanidination has been described recently. ${ }^{1}$

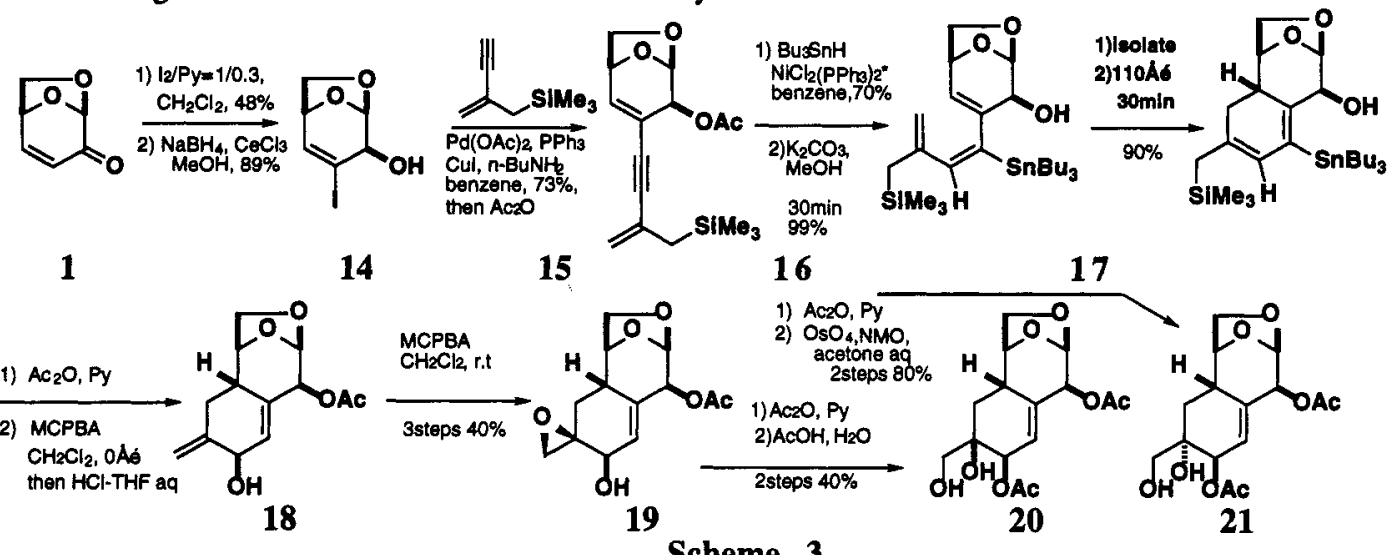

Scheme 3

In search of compounds with channel protein-blocking activity, we studied inhibitors to protein phosphatase. The improved total synthesis of one of the compounds, tautomycin having a strong inhibitory action to protein phosphatases (Type 2A and Type 1) is discussed. Analogs with or without functions necessary for inhibitory action are to be reported with special reference to the molecular shape of these compounds and activity relationship. As may be noted in the following two structures, both strong inhibitors to protein phosphatase, they have similar spiro ring systems which are pseudo-enantiomeric to each other. Our synthetic interest was to develop a methodology to provide both of the pseudo-enantiomers from D-glucose or its derivatives as starting material.

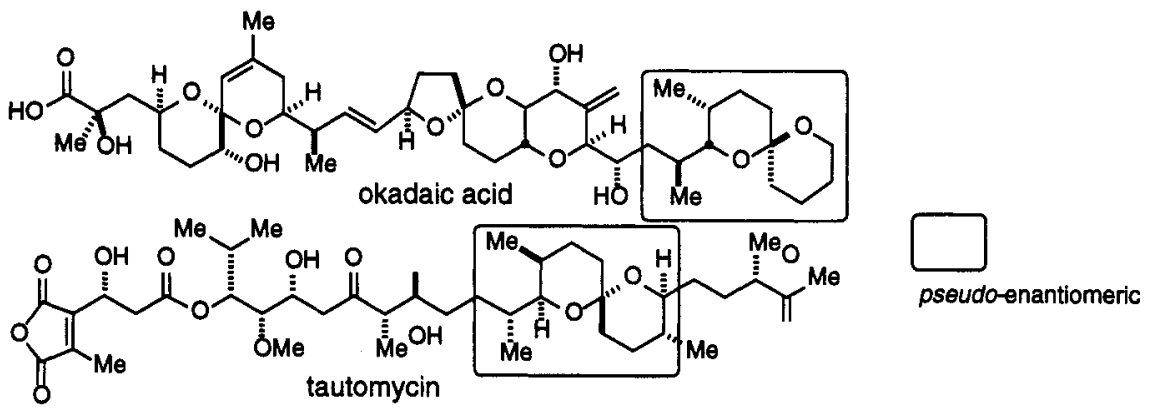

The concept of the enantio-switching method is illustrated below. We have already reported the methodology named as heteroconjugate addition, which was the candidate to achieve the above possibility. ${ }^{3}$ Namely, the C-glycosidation of acetylenic groups to glucals proceeds in a completely alpha-axial manner; 
which product is converted to the heteroolefin by hydroxylation and oxidation. Alternative synthesis includes epimerization of the acetylenic group to a beta-equatorial configuration through biscobal thexacarbonyl complex and acidic treatment.

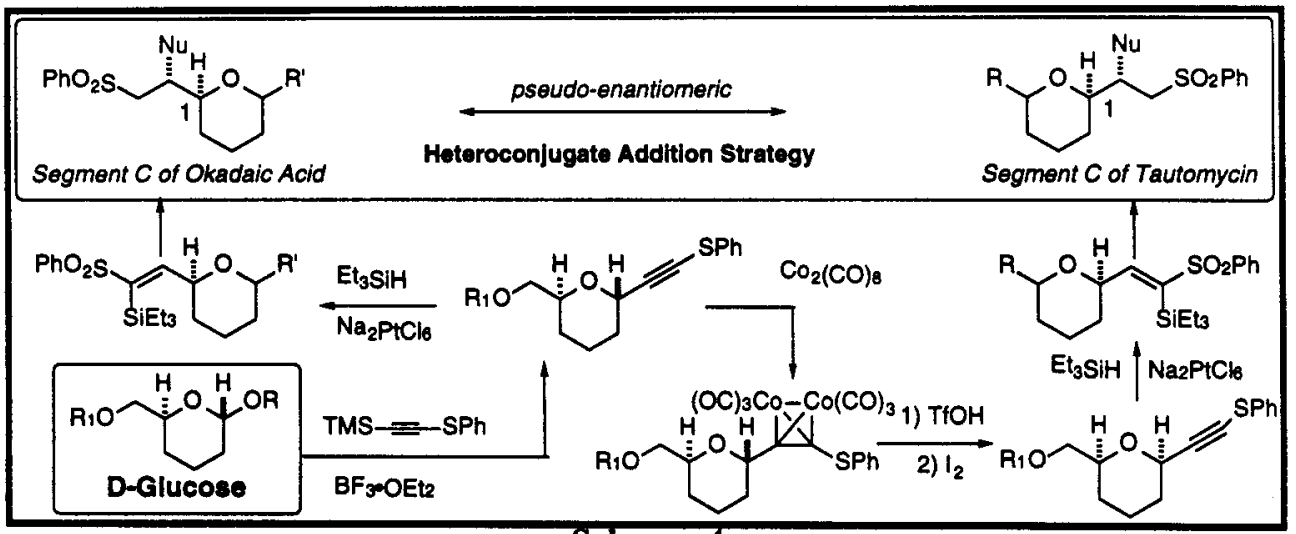

Scheme 4

Acyclic allylic strain as shown in Fig. 1 is re-drawn with the heteroolefin at the C-1 position with alpha and beta orientations (Fig. 2). The original method was developed for maytansine synthesis, and the diastereo-switching method was developed in the total synthesis of okadaic acid. Recently, we have established a method to switch the product in either of enantiomers via the heteroolefin as shown below (Fig. 2).

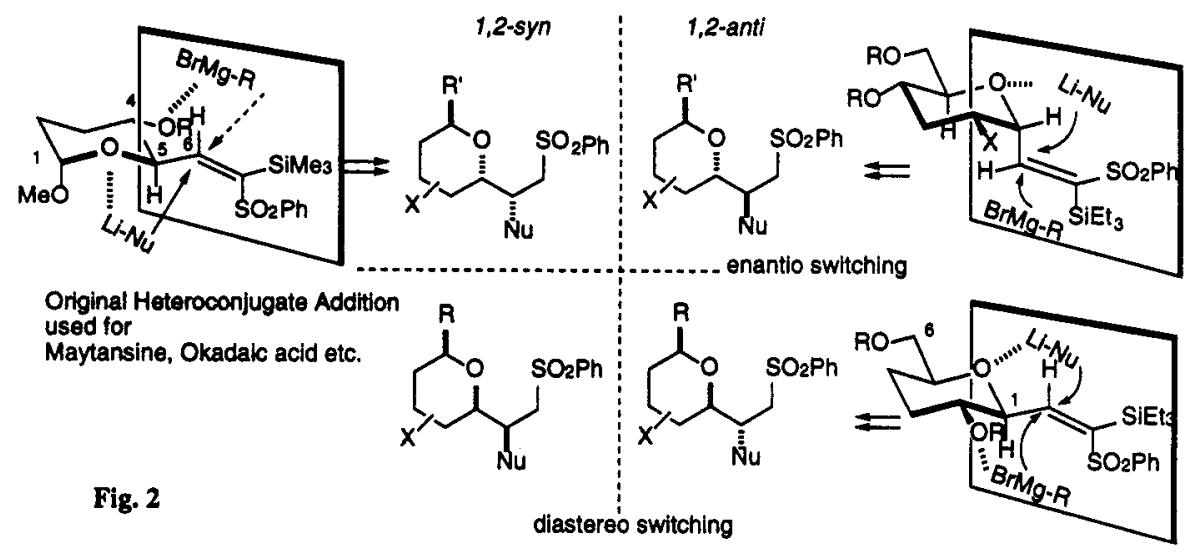

This method was indeed applied to the synthesis of the two sub-segments $(\mathrm{C} 1$ and $\mathrm{C} 2$, not indicated), and each of which was coupled to the other to give Segment $C .4,8$ Coupling of Segment $C$ first with Segment B and finally with Segment A led us to conclude the total synthesis. 5,6 The following gave further improvement of the coupling steps; the esterification of Segment $A$ to the diol (without protection) represented considerable progress. The improved total synthesis was achieved in 3 steps directly from the maleic anhydride (cf. previous esterification was achieved via furan derivative) in an overall yield of $53 \%$.<smiles>COc1ccc(COC(C(C)C)[C@H](OC)[C@H](O)CC2([C@H](C)C3COC(C)(C)O3)SCCCS2)cc1</smiles>
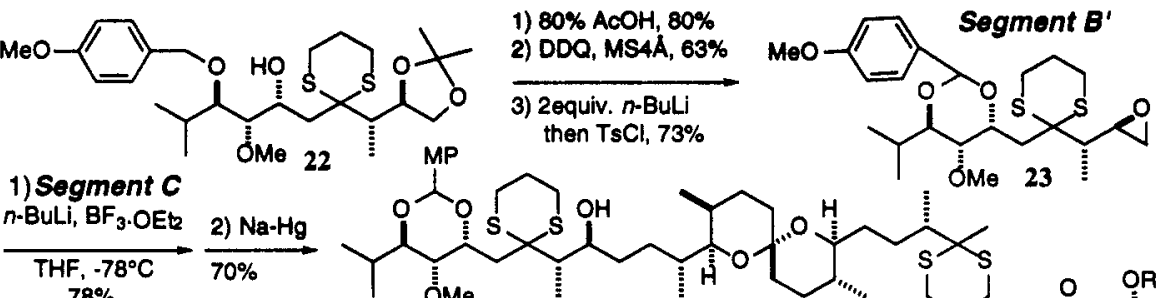

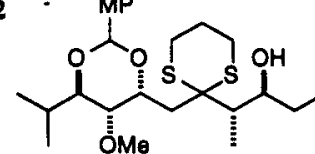

$78 \%$

\begin{tabular}{c} 
1) TBSOTI, \\
$85 \%$ \\
\hline $\begin{array}{c}\text { 2) } \mathrm{PPTS} \text {. } \\
73 \%\end{array}$
\end{tabular}<smiles>CCC(O[Na])C(C)C1(CC(O)C(O)[C@H](OC)C(O)C(C)C)OCCCS1</smiles>
Segment $B^{\prime}+C \quad 24$<smiles>CC1=C([C@H](O)CC(=O)O)C(=O)OC1=O</smiles> 

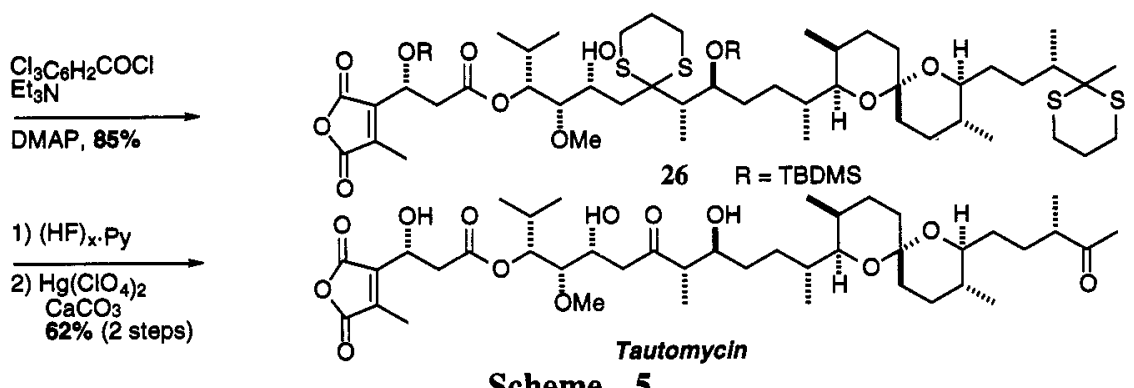

Scheme 5

This improvement prompted us to synthesize other analogs useful for mechanistic studies. One of the candidates is a hybrid molecule between tautomycin and okadaic acid, named as okadamycin. The enantioswitching method allowed us to synthesize Segment $C$ of okadaic acid (28) (scheme not shown). Similar coupling between ttm-segment B (27) and ok-segment C (28) provided 29, which was esterified with 30 to give the ester 31 in $86 \%$ yield. Deprotection gave okadamycin (32), which showed strong inhibitory activity toward PP2A.

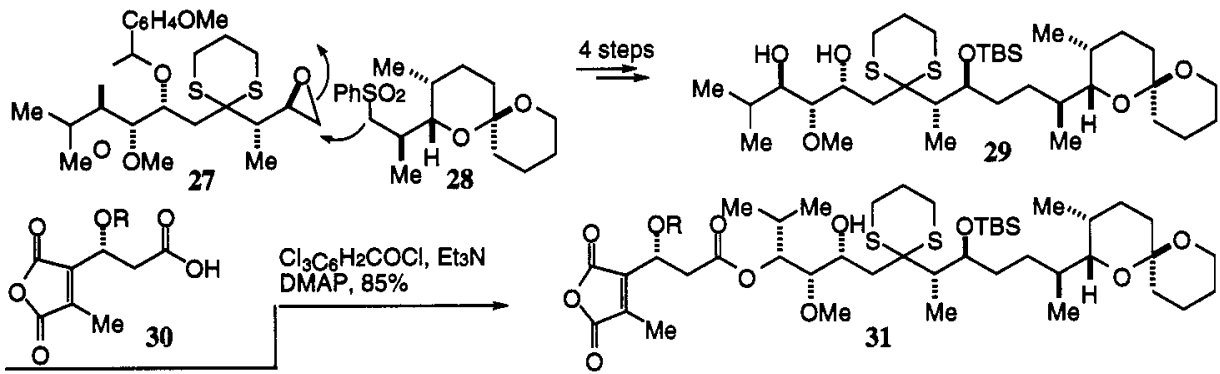

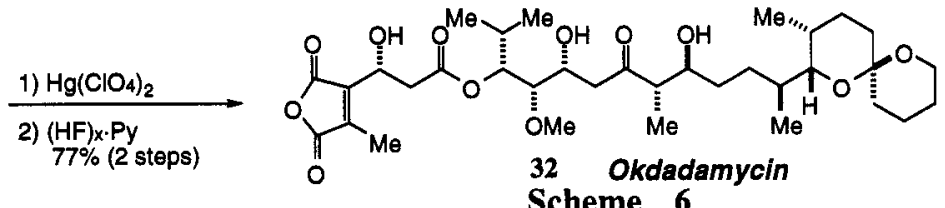

Scheme 6

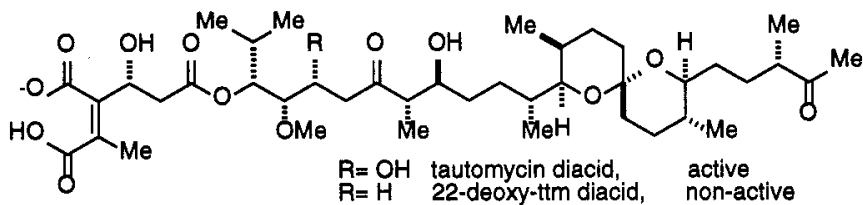
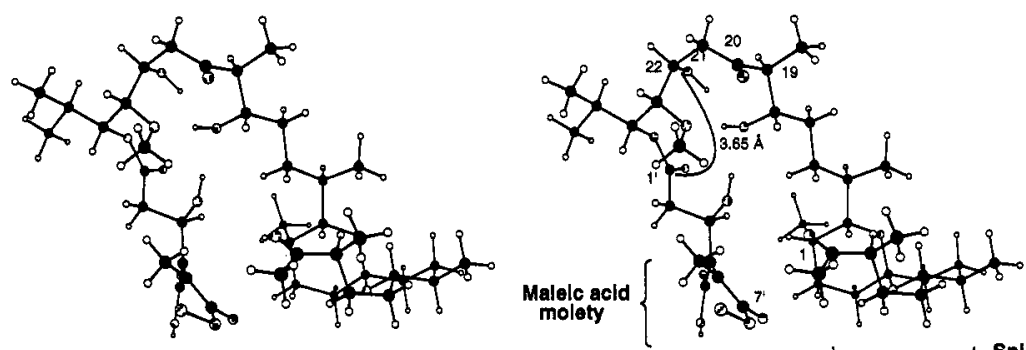

Fig. 3 Stereo view of proposed 3D structure of tautomycin diacid

The protein phosphatase inhibitory activity is now measurable by means of bioluminescence using luciferin phosphate and immobilized luciferase system without radioactive phosphorylated protein. ${ }^{7}$ This conventional method is applicable to both PP2A and PP1, 9 leading us to the conclusion that the anhydride is not the active form and that the corresponding diacid is the only active one. The hydroxy group at the C21 position is very critical. ${ }^{10}$ Those compounds without this $\mathrm{OH}$ or dehydrated compounds are all completely inactive. On the other hand, NMR analysis of tautomycin diacid in water solvent revealed that the higher structure of tautomycin is a folded conformation, in which this $21-\mathrm{OH}$ sticks outside and at the 
same time is approachable ( $3.6 \mathrm{~A}$ distance) to the ester carbonyl carbon. This ester does trans-esterify onto the $21-\mathrm{OH}$ to give only the dehydration product. No ester hydrolysis and the subsequent dehydration can be found with the 21-deoxy compound under the same alkaline condition. These findings support the 3D structure of ttm as presented in Fig. 3.

Synthetic efforts toward ciguatoxin is the next subject. We wish to synthesize this target molecule using a similar approach to cyclize the various $(5,6,7,8$ and 9$)$ membered ether rings. We became interested in constructing the poly-oxy-ethylene unit by cyclization of the ether ring at the $\mathrm{C}-\mathrm{O}$ bond formation. 12

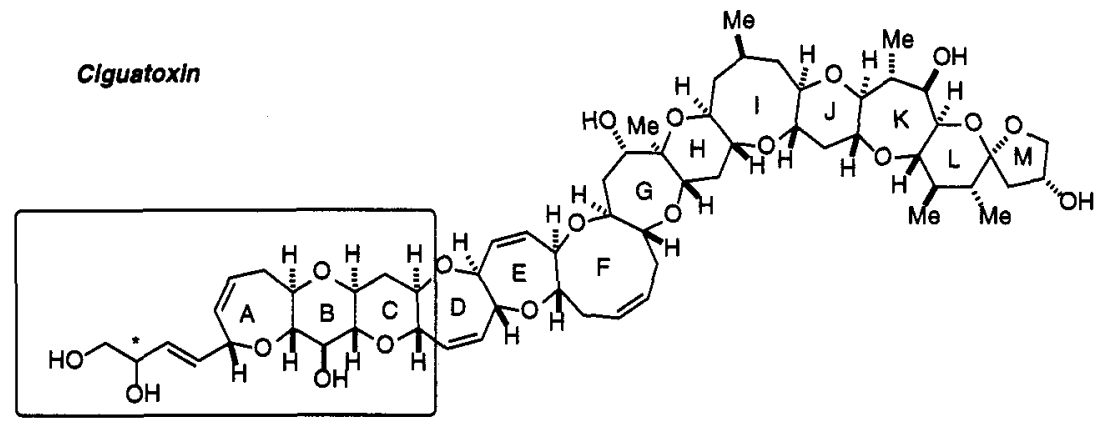

The following Scheme 7 shows the role of the nature of the 9-membered ether ring in the above attempt for cyclization; thus, the precursor open chain cation may not approach the $\mathrm{OH}$ due to trans annular interactions and conformational problems. On the other hand, the cation that may be stabilized by the biscobalthexacarbonyl complex would provide the ether ring due to the bulky complex effect which would bring the reacting sites together. ${ }^{12,13,14,15,16}$

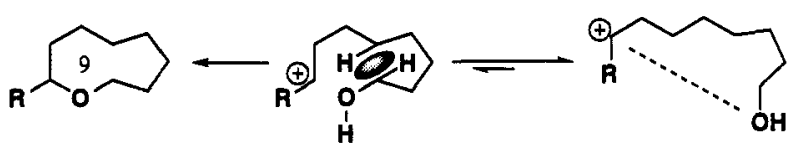

\section{Scheme 7}

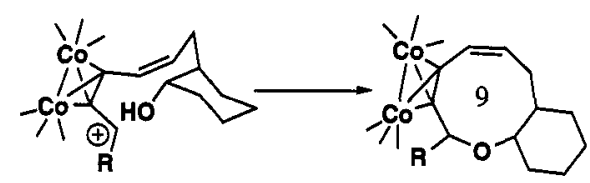

This idea using the Nicholas reaction was tested on the undermentioned model compounds, and in fact, we obtained the corresponding $6 / 7,6 / 8$ and $6 / 9$ bicycle systems in fairly good yields. This shows that the molecular shape significantly affects the reactivity. The principle of this reaction is now under rapid progress for the synthesis of various parts of the ciguatoxin molecule. 17

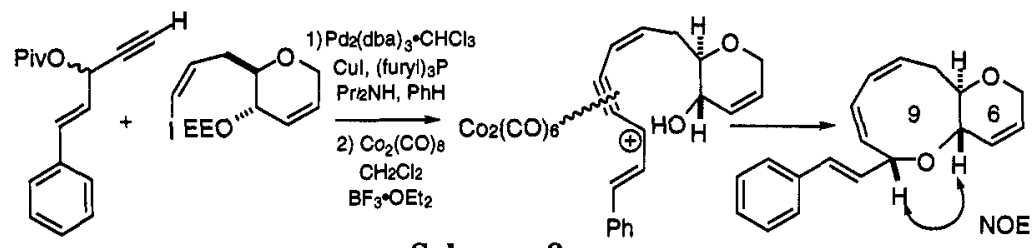

Scheme 8

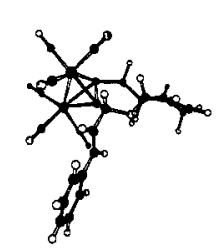

Fig. 6

Synthesis of the B-ring of CTX has to be achieved since the absolute stereochemistry is still open, so that an enantio-switchable route is required. The following compound is targeted to demonstrate this possibility, and has in fact been synthesized. 18<smiles>[2H]C1C(CC#C)O[C@H](CCC[Se-])[C@@H](O)[C@@H]1O</smiles>

33<smiles>O[C@@H]1[C@H](O)[C@H](CI)O[C@H](CCC[Hg])[C@H]1O</smiles>

35

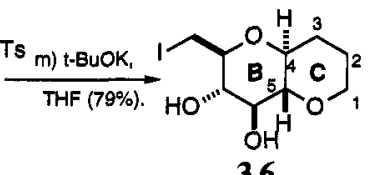

36<smiles>C#CC[C@H]1O[C@H](CCCOC(C)(C)C)C(O)C(O)C1O</smiles>

34

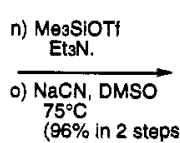

( $96 \%$ in 2 steps). p) DIBAL-H

$\left.\mathrm{CH}_{2} \mathrm{C}\right|_{2}(96 \%)$

q) $\mathrm{CBr}_{4}, \mathrm{PPh}_{3}$ then Et3N. 


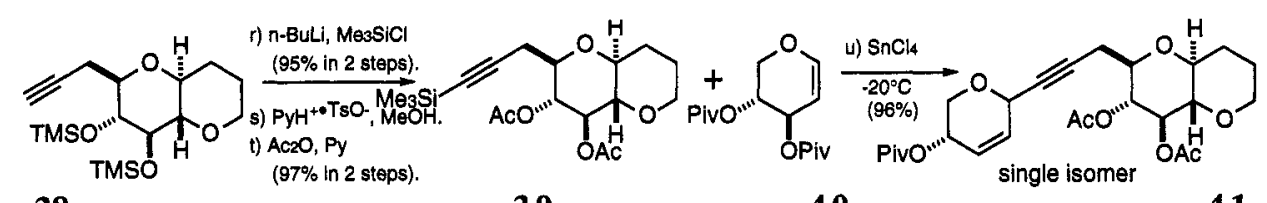

38

39

40

41

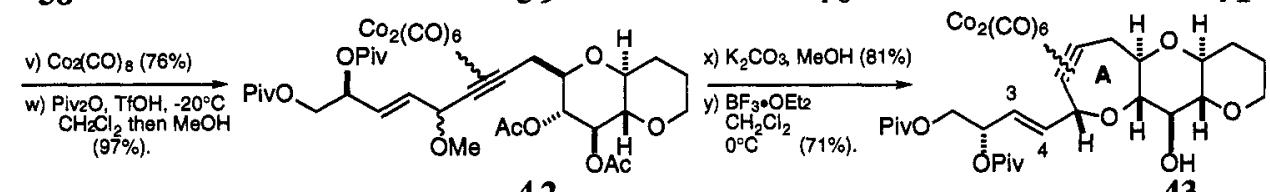

42

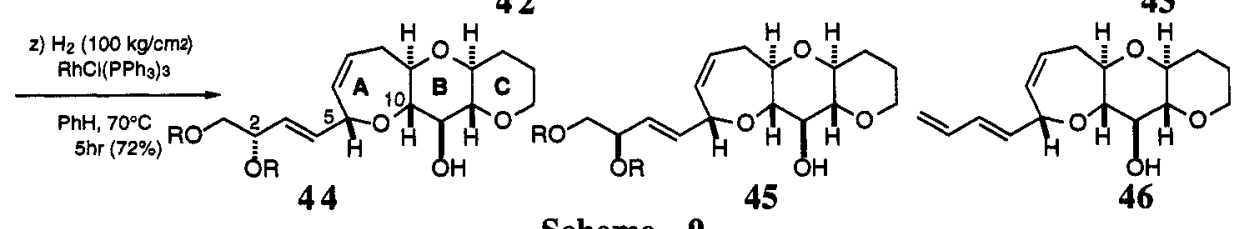

Scheme 9

The C-glycosidation of $\mathbf{3 9}$ by silyl-acetylene to glucal type function in $\mathbf{4 0}$ was another key reaction. The cationic intermediate allowed the conversion of the cis-olefin in $\mathbf{4 1}$ into the corresponding trans-open chain molecule (42) which was finally cyclized and decomplexed to the $2 S, 5 S$ diol 44 . Similarly $2 R, 5 S$ was synthesized. These syntheses accelerate the synthesis of other portion of ciguatoxin. ${ }^{19}$

Acknowledgment Authors are indebted to the Grant-in-aid for Scientific Research from Ministry of Education, Science and Culture.

\section{References}

(1) (a) Yamamoto, N.; Isobe, M. Chemistry Lett, 1994, (\#12) 2299-2302. (b) Yamamoto, N.; Nishikawa, T.; Isobe, M. Synlett, (Special Issue for Prof. Stork), 1995, \#5, 505-6.

(2) Other studies on TTX: (a) Kishi, Y.; Fukuyama. T.; Aratani, M.; Nakatsubo, F.; Goto, T.; Inoue, S.: Tanino, H.; Sugiura, S.: Kakoi, H. J. Am. Chem. Soc., 1972, 94, 9217, 9219. (b) FraserReid, B.; Alonso, R. A.; McDevitt, R. E.; Rao, B.; Venkateswara; Vite, G. D.; Zottola, M. A. Bull. Soc. Chim. Belg. 1992, 101(7), 617-626. (c) Fraser-Reid, B.; Alonso, R. A.; McDevitt, R. E.; Rao, B.; Venkateswara; Vite, G.' D.; Zottola, M. A. J. Am. Chem. Soc., 1993, 115(15) 66666672. (d) Burgey, C. S.; Vollerthun, R.; Fraser-Reid, B. J. Org. Chem., 1996, 61, 1609-1618. (e) Sato, K.; Kajihara, Y.; Nakamura, Y.; Yoshimura, J. Chem. Lett., 1991, 1559-1562.

(3) Isobe, M; Jiang, Y-M.; Tetrahedron Lett, 1995, 36 ( $\# 4$ ) 567-570.

(4) Jiang Y.; Ichikawa, Y.; Isobe, M. Synlett, 1995, \#3, 285-288.

(5) Ichikawa, Y.; Tsuboi, K.; Jiang, Y.; Naganawa, A.; Isobe, M. Tetrahedron Lett., 1995, 36 (\#39), $7101-7104$.

(6) Other studies on TTM: (a) Oikawa, H.; Oikawa, M.; Ueno, T.; Ichihara, A. Tetrahedron Lett., 1994, 35, 4809. (b) Nakamura, S-I.; Shibasaki, M. Tetrahedron Lett., 1994, 35, 4145.

(7) (a) Isobe, M.; Sugiyama, Y.; Ito, T.; Ohtani, I. I.; Toya, Y.; Nishigori, Y.; Takai, A. Biosci. Biotech. Biochem. 1995, 59 (\#12), 2235-2238. (b) Takai, A.; Sasaki, K.; Nagai, H.; Mieskes, G.; Isobe, M.; Isono, K.; Yasumoto, T. Biochemical Journal, 1995, 306 (\#3), 657-665.

(8) Jiang, Y.; Isobe, M.' Tetrahedron, 1996, 52 (\#8), 2877-2892.

(9) Sugiyama, Y.; Ohtani, I. I.; Takal, A.; Isobe, M. Biosci. Biotech. Biochem., 1996, 60 1260-4. (10) Sugiyama, Y.; Ohtani, I. I.; Isobe, M.; Takai, A.; Ubukata, M.; Isono, K. BioMed. Ćhem. Lett.,

(11) Tanaka, S.; Isobe, M. Tetrahedron, 1994, 50 (\#19), 5633-5644.

12) Tanaka, S; Isobe, M. Tetrahedron Lett., 1994, 35 (\#42) $7801-7804$.

13) Isobe, M.; Yenjai, C.; Tanaka, S. Synlett, 1994, (\#11), 916-918.

14) S. Tanaka, N. Tatsuta, O. Yamashita, M. Isobe, Tetrahedron, 1994, (\#50), 12883-12894.

15) Tanaka, S.; Isobe, M. Synthesis, 1995, \#7, 859-862.

16) Hosokawa, S.; Isobe, M. Synlett, 1995, ( $\# 11)$, 1179-1180.

$17)$ Isobe, M.; Hosokawa, S.; Kira, K. Chem. Lett., 1996, $473-474$.

18. Hosokawa, S.; Isobe M. Synlett, 1996, (\#4) 351-352.

(19) Other studies on CTX: (a) Suzuki, T.; Sato, O.; Hirama, M.; Yamamoto, Y.; Murata, M.; Yasumoto, T.; Harada, N. Tetrahedron Lett., 1991, 32(\#35), 4505-8. (b) Sato, O.; Hirama, M. Synlett 1992 , (\#9), 705-7. (c) Oguri, H.; Hishiyama, S.; Oishi, T.; Hirama, M.' Synlett. 1995, (\#12), 1252-4. (d) Hirama, M. 1996, . (e) Ravelo, J. L.; Regueiro, A.; Martin, J. D. Tetrahedron Lett., 1992 33 (\#23), 3389-92. (f) Soler, M. A.; Palazon, J. M.; Martin, V. S. Tetrahedron Lett., 1993 , 34(\#34), 5471-4. (g) Alvarez, E.; Perez, R.; Rico, M.; Rodriguez, R. J. Org. Chem., 1996, 61(\#9), 3003-16. (h) Alvarez, E.; Delgado, M.; Diaz, Märia T.; Hanxing, L.; Perez, R.; Martin, J. D. Tetrahedron Lett., 1996, 37(\#16), 2865-8. (i) Ravelo, J. L.; Regueiro, A.; Rodriguez, E.; de Vera, J.; Martin, J. D. Tetrahedron Lett., 1996, $37(\# 16), 2869-72$ 